\title{
Mysterious attendance cycles in Cory's shearwater, Calonectris diomedea: an exploration of patterns and hypotheses
}

\author{
José P. Granadeiro $^{\mathrm{a}, *}$, Hany Alonso ${ }^{\mathrm{b}, 1}$, Vitor Almada ${ }^{\mathrm{b}, 1}$, Dília Menezes ${ }^{\mathrm{c}, 2}$, \\ Richard A. Phillips ${ }^{\mathrm{d}, 3}$, Paulo Catry ${ }^{\mathrm{b}, 1}$ \\ a Centro de Biologia Ambiental, Museu Nacional de História Natural, Universidade de Lisboa \\ ${ }^{\mathrm{b}}$ Eco-Ethology Research Unit, Instituto Superior de Psicologia Aplicada \\ ${ }^{\mathrm{c}}$ Parque Natural da Madeira \\ ${ }^{\mathrm{d}}$ British Antarctic Survey, Natural Environment Research Council
}

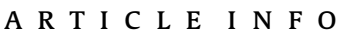

\section{Article history:}

Received 25 June 2009

Initial acceptance 30 July 2009

Final acceptance 17 September 2009

Available online 17 October 2009

MS. number: 09-00427

\section{Keywords:}

Berlenga Island

Calonectris diomedea

Cory's shearwater

logger

periodicity

seabird

Selvagem Grande

social interaction

synchrony
Several species of seabirds show cyclic patterns of attendance at their nesting colonies. We examined the patterns of variation in the numbers of Cory's shearwater at three colonies (two oceanic and one located on the continental shelf), including the world's largest, at Selvagem Grande, Madeira, Portugal and considered several hypotheses concerning their causal mechanisms. At Selvagem Grande, cycles were exceptionally marked and regular, with a periodicity ranging from 7.8 to 11 days, and involved both breeders and nonbreeders. In contrast, variation in numbers was aperiodic at a nearby and much smaller colony (Selvagem Pequena), and also at the colony located off the Portuguese coast (Berlenga Island). We found no relationships between number of birds ashore and environmental variables such as wind direction and speed or lunar cycle. Cycles did not seem to be driven by oscillations in food availability or accessibility, given that they did not correlate with daily chick growth rates (which were acyclic) or diet. Despite their regularity, cycles were slightly out of phase in different sectors of Selvagem Grande, which suggests that social interactions at the colony could act as an entrainment agent for an endogenous rhythm, and so cycles are probably more likely to occur in large and dense colonies. Observations are consistent with the hypothesis that cycles facilitate social interactions by maximizing the probability of encounters at the colony. However, the exact mechanisms through which these remarkable cycles are controlled are still completely unknown, and clearly further research is needed.

(c) 2009 The Association for the Study of Animal Behaviour. Published by Elsevier Ltd. All rights reserved.
Many species of seabirds gather in large and dense colonies to breed. Throughout the nesting season, the numbers of birds visiting the colonies typically vary widely, but in some species there are very clear cyclic patterns of attendance. These are particularly conspicuous in some well-studied alcids, such as the puffin, Fratercula arctica, and the guillemot, Uria aalge (e.g. Harris 1984; Wilhelm \& Storey 2002 and references therein), but have also been recorded in several petrel species (Bretagnolle 1988, 1990; Hatch 1989; Mougin et al.

\footnotetext{
* Correspondence: J. P. Granadeiro, Centro de Biologia Ambiental, Museu Nacional de História Natural, Universidade de Lisboa, Rua da Escola Politécnica 58, 1269 102 Lisboa, Portugal.

E-mail address: jpgranadeiro@fc.ul.pt (J.P. Granadeiro).

${ }^{1} \mathrm{H}$. Alonso, V. Almada and P. Catry are at Instituto Superior de Psicologia Aplicada, Rua Jardim do Tabaco 34, 1149-041 Lisboa, Portugal.

2 D. Menezes is at Parque Natural da Madeira, Quinta do Bom Sucesso, Caminho do Meio, 9050-251 Funchal, Portugal.

${ }^{3}$ R. A. Phillips is at British Antarctic Survey, High Cross, Madingley Road, Cambridge CB3 OET, U.K.
}

2000). During such cycles, the numbers of birds ashore can vary several-fold during the course of a few days and hence such variation is very obvious even for the casual observer. Surprisingly, the significance of, and regulatory mechanisms underlying, attendance cycles in seabirds are virtually unknown (Harris 1984; Weidinger 1996). Indeed, the patterns of cyclic attendance have been described quantitatively for only a few species and not much is known about basic aspects such as intra- and interspecific variation, or periodicity and amplitude of cycles. In addition to being an obvious gap in our fundamental knowledge of seabird behaviour, this issue has practical relevance, for example for the design of monitoring programmes based on counts of birds seen ashore (e.g. Piatt et al. 1990; Hatch 2002; Harding et al. 2005). Below, we detail a set of nonexclusive hypotheses that may explain this behaviour and some of the potential underlying synchronization mechanisms.

Cyclic patterns of colony attendance may represent a direct response to prevailing weather conditions, particularly wind direction and/or intensity (hereafter referred to as the "weather hypothesis'). Oscillations in wind direction may favour travel to or 
from distant feeding grounds. Weidinger (1996) found that the attendance of Cape petrel, Daption capense, during the breeding period was lower during periods of stronger southeast winds, possibly facilitating access to their preferred foraging grounds. Also, variation in wind strength may constrain the movements of birds that rely to a large extent on dynamic soaring to travel (Furness \& Bryant 1996). Furthermore, many petrels are known to adjust their movement patterns and strategies as a function of wind conditions encountered at both small and large scales (e.g. Weimerskirch et al. 2000; Felicísimo et al. 2008).

An alternative hypothesis is that the number of birds ashore may be linked with regular variation in food availability, possibly driven by a cyclic oceanographic phenomenon (the 'oceanography/ food availability hypothesis'). When food is abundant close to the colony, birds may come ashore more often, whereas when resources become scarcer they might be forced to forage further afield, and will be less likely to be seen at the colony. Alternatively, during short periods of food scarcity, birds may simply postpone foraging until weather conditions improve (e.g. Piatt et al. 1990).

Mougin et al. (2000) suggested that cyclic attendance patterns could represent a mechanism through which birds increase the likelihood of meeting relevant social contacts at the colony, such as partners and competitors for nesting sites, which we refer to as the 'social encounters hypothesis'. Regular attendance cycles were more apparent in species or populations of petrels with longer periods between return from migration and egg laying. This situation reflects the relative probability of individuals within a pair meeting at the nest site purely by chance. This supports the 'social encounters hypothesis', because while birds with a short prelaying period have very high overall levels of attendance over a short time interval (and hence meet frequently at the colony), birds with a long preincubation period cannot live exclusively on accumulated body reserves and hence need to absent themselves on often long foraging trips. This hypothesis might explain the function of the cyclic behaviour, but tells us nothing about the mechanisms by which synchronization is achieved.

Synchronized attendance at the colony for social purposes needs to be driven by external or internal cues, or by a combination of both. In relation to synchronization mechanisms, one possibility is that attendance cycles result from an internal rhythm, the 'endogenous rhythm hypothesis'. This hypothesis predicts that cycles should be regular and with a similar periodicity in different years, assuming the stimulus is an internal pacemaker of some description. Entrainment could also be provided by the intensity of the social interactions at the colony: 'the social stimulus hypothesis'. If social interactions were the synchronizing agent, the prediction can be made that disjunct colonies or subcolonies would show imperfect synchronization or no synchronization at all. Finally, the possibility has to be considered that attendance patterns might simply be artefacts of the behaviour and/or detectability of birds at the colony (e.g. later time of arrival, less conspicuous behaviour) rather than to their actual presence (the 'visibility hypothesis').

The Cory's shearwater is a medium-sized petrel which is strictly nocturnal at most of its breeding locations. However, at Selvagem Grande, a remote subtropical island ca. $300 \mathrm{~km}$ south of Madeira, Portugal, birds start to come ashore well ahead of the sunset. This is the world's largest colony of this species with ca. 30000 breeding pairs (Granadeiro et al. 2006) and it is also noteworthy in that birds at this site exhibit a very regular and pronounced cyclic pattern of attendance. The duration of cycles on Selvagem Grande has been estimated previously (Jouanin et al. 1989; Mougin et al. 2000) and shows a remarkable interannual consistency. However, a significant part of the data published consists of relatively short time series of ranked abundance values rather than true counts, and were obtained mainly during incubation (June-July). Furthermore, there are no comparative data from other colonies of this species and no exploration of the possible role of environmental drivers.

We addressed the hypotheses outlined above using data collected over an extended period at Selvagem Grande, which is located in a low-productivity pelagic environment, and compared these time series with data collected concurrently on a nearby island, Selvagem Pequena, and with Berlenga, a colony located on the continental shelf of the mainland Portuguese coast. We examined several predictions deriving from each of the hypotheses, as a means to try to explain cyclic attendance behaviour in Cory's shearwater in this region and potentially in other species.

\section{METHODS}

\section{Study Area and Bird Counts}

Fieldwork was carried out in the Selvagens archipelago $\left(30^{\circ} 07^{\prime}\right.$ $\mathrm{N}, 15^{\circ} 56^{\prime} \mathrm{W}$ ), and at Berlenga Island ( $\left.39^{\circ} 24^{\prime} \mathrm{N}, 9^{\circ} 30^{\prime} \mathrm{W}\right)$, a small island ca. $10 \mathrm{~km}$ off the coast of mainland Portugal (Fig. 1). At ca. 260 ha in size, Selvagem Grande is the largest of the three islands that constitute the Selvagens archipelago. This island alone sustains a population of Cory's shearwaters estimated at ca. 30000 breeding pairs (Granadeiro et al. 2006). In contrast, Selvagem Pequena, located ca. $20 \mathrm{~km}$ southwest of Selvagem Grande with a total area of ca. 20 ha, holds only an estimated 200 pairs (Equipa Atlas 2008). The population on Berlenga is estimated at a few hundred breeding pairs (Equipa Atlas 2008).

To quantify the number of birds visiting the colony, we set up a three-stage transect in 2006, which ran from the plateau of Selvagem Grande down to the field station, at sea level, with a total length of ca. $500 \mathrm{~m}$. The legs of the transect roughly corresponded to obvious changes in the direction of the path as a result of a change in the type of habitat. The first leg was at the plateau (ca.100 m above sea level), along a colony with nests in a stone wall, and had a length of ca. $100 \mathrm{~m}$; the second followed the cliff edge (length ca. $170 \mathrm{~m}$ ) and the third included the descent to the field station (length ca. $250 \mathrm{~m}$ ). During our trips to the island (in different periods between 2006 and 2008; dates are given in Table 1 and Fig. 3 in the Results), this transect was walked daily exactly $15 \mathrm{~min}$ before the time of sunset (obtained from Observatório Astronómico de Lisboa, http://www.oal.ul.pt/) and all birds on the ground within a $25 \mathrm{~m}$ band were counted. Birds that were inside their burrows (resting, incubating or feeding the chicks) were not included. Overall, it took about 20 min to walk the whole transect. A similar procedure was adopted in Selvagem Pequena in 2007 and 2008 (dates are given in Table 1) with a transect ca. $100 \mathrm{~m}$ long (bandwidth of $12.5 \mathrm{~m}$ for each side, owing to differences in the areas used by birds on land). Cory's shearwaters are strictly nocturnal on this island and hence the counts started $1.5 \mathrm{~h}$ after sunset every day. In 2006, counts were also carried out on Berlenga Island, $1.5 \mathrm{~h}$ after sunset, along a transect through one of the main subcolonies (ca. $150 \mathrm{~m}$, variable bandwidth, according to terrain characteristics). At both Selvagem Pequena and Berlenga a low-power light source was used to count birds on the ground. Cory's shearwater are generally tame birds and remained undisturbed to relatively quiet and slow movements in their vicinity and so walking the transects had virtually no influence on their behaviour or in the colony.

All ringing and manipulations of adult birds and chicks were carried out under licences from the Institute of Nature Conservation, Lisbon, and from the Service of Madeira Natural Parque, Funchal.

\section{Wind and Lunar Phase Data}

To test for an association between the number of shearwaters ashore on Selvagem Grande and Selvagem Pequena and wind 


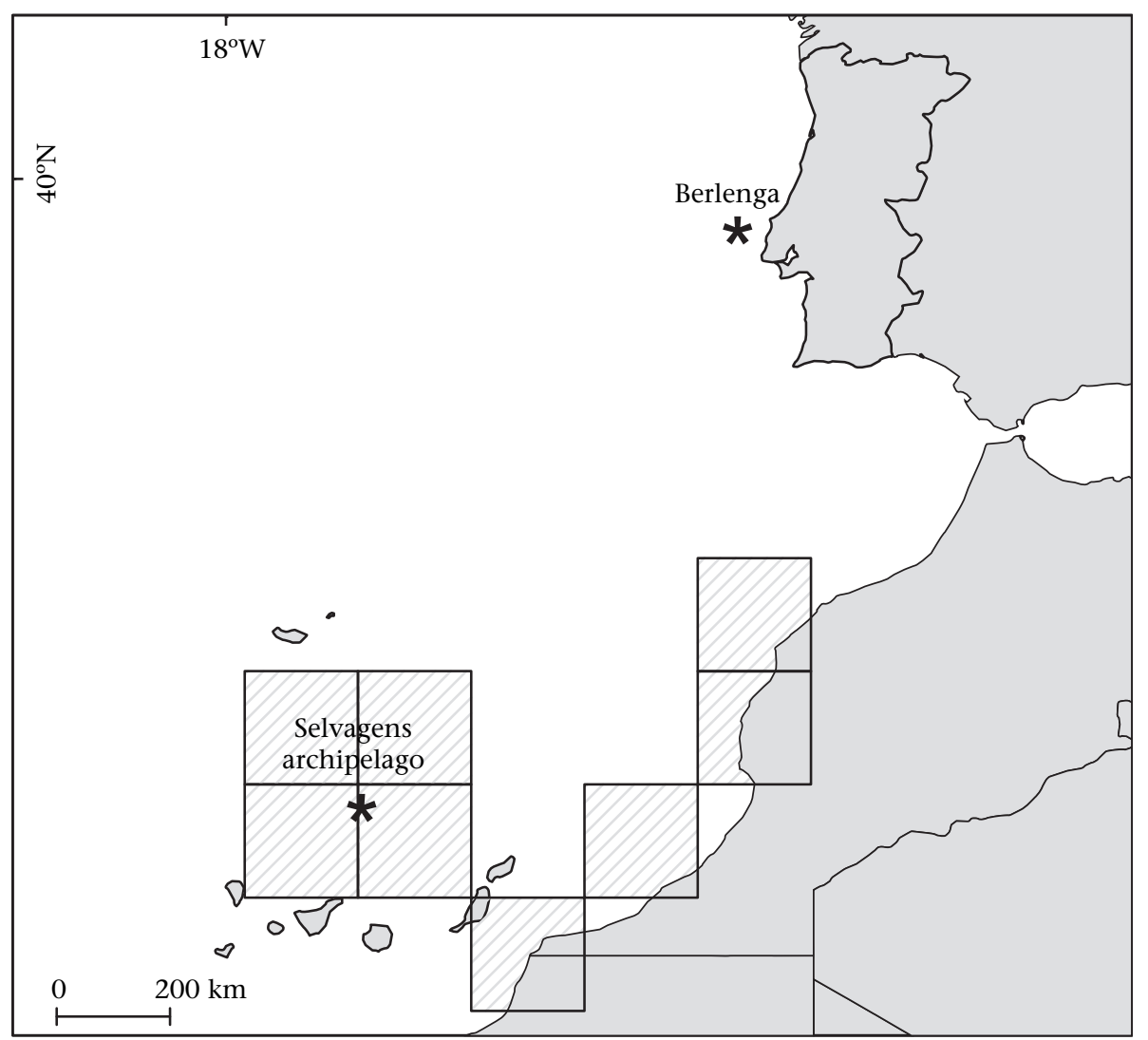

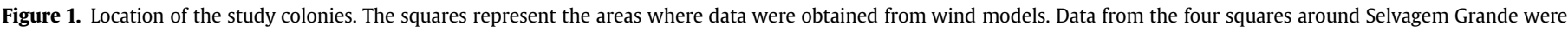
averaged to calculate 'local winds', and the remaining squares were used to calculate wind on the 'African coast' (see Methods for details).

conditions, we obtained the daily $u$ (east-west) and $v$ (northsouth) components of wind vectors (at $10 \mathrm{~m}$ ) of surface flux data derived from NCEP/NCAR Reanalysis 1 (http://www.cdc.noaa.gov/ cdc/data.ncep.reanalysis.surfaceflux.html). The values represent modelled wind parameters for a square area of approximately $200 \times 200 \mathrm{~km}$. We calculated the daily wind parameters for all our counting periods as the average of four such quadrats around the Selvagens archipelago ('local wind') and also as the four quadrats closest to the African coast, from ca. $26^{\circ} 30^{\prime} \mathrm{N}$ to $34^{\circ} 30^{\prime} \mathrm{N}$ ('African wind', see Fig. 1). The 'local' area roughly encompasses the distances travelled by foraging shearwaters making short trips (Magalhães et al. 2008), whereas the 'African coast' areas include the regions used during incubation at Selvagem Grande or on long foraging trips (e.g. Mougin \& Jouanin 1997; V. Paiva, personal communication; our unpublished data). We also analysed wind data for these two areas for the periods 1 April-15 May (prelaying) and 10 June- 1 September (incubation and chick rearing) each year from 1998 to 2008, searching for patterns indicating any type of long-term average periodicity in wind components.

Dates of new and full moons for our study periods were obtained from Observatório Astronómico de Lisboa (http://www. oal.ul.pt/), and an index of the moon phase on each day was derived from a sine-wave model with a period of 29.53 days ( 1 representing full moon and -1 representing new moon). This approximation was very precise, given the relatively short duration of the periods of interest.

Table 1

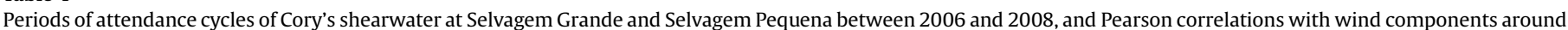
the islands ('local wind') and on the African coast

\begin{tabular}{|c|c|c|c|c|c|c|c|c|c|}
\hline \multirow[t]{2}{*}{ Site (year) } & \multirow[t]{2}{*}{ Dates (no. of days) } & \multirow[t]{2}{*}{ Phase } & \multirow[t]{2}{*}{ Period (days) } & \multicolumn{3}{|c|}{$\begin{array}{l}\text { Correlation with local wind } \\
\text { components }\end{array}$} & \multicolumn{3}{|c|}{$\begin{array}{l}\text { Correlation with wind } \\
\text { components on African coast }\end{array}$} \\
\hline & & & & North & West & Intensity & North & West & Intensity \\
\hline Selvagem Grande (2006) & 19 Jun-11 Aug (54) & Incubation and chick rearing & 9.0 & -0.07 & -0.03 & -0.17 & -0.04 & -0.03 & -0.20 \\
\hline Selvagem Grande (2007) & $\begin{array}{l}2 \text { Apr-18 May (47) } \\
22 \text { Jun-22 Aug (62) }\end{array}$ & $\begin{array}{l}\text { Prelaying period } \\
\text { Incubation and chick rearing }\end{array}$ & $\begin{array}{l}7.8 \\
10.0\end{array}$ & $\begin{array}{r}-0.13 \\
\mathbf{0 . 4 4}\end{array}$ & $\begin{array}{r}-0.29 \\
0.54\end{array}$ & $\begin{array}{r}-0.04 \\
0.08\end{array}$ & $\begin{array}{r}-0.18 \\
\mathbf{0 . 3 3}\end{array}$ & $\begin{array}{r}-0.31 \\
0.34\end{array}$ & $\begin{array}{l}-0.12 \\
-0.17\end{array}$ \\
\hline Selvagem Pequena (2007) & $\begin{array}{l}10 \text { Jun-1 Jul (22) } \\
25 \text { Jul-11 Sept (49) }\end{array}$ & $\begin{array}{l}\text { Incubation } \\
\text { Chick rearing }\end{array}$ & $\begin{array}{l}\text { NS } \\
\text { NS }\end{array}$ & $\begin{array}{l}0.06 \\
\mathbf{0 . 3 2}\end{array}$ & $\begin{array}{l}0.10 \\
0.22\end{array}$ & $\begin{array}{r}-0.02 \\
0.07\end{array}$ & $\begin{array}{r}-0.01 \\
0.19\end{array}$ & $\begin{array}{l}0.05 \\
0.24\end{array}$ & $\begin{array}{l}-0.15 \\
-0.15\end{array}$ \\
\hline Selvagem Grande (2008) & $\begin{array}{l}10 \text { Jun-1 Jul (22) } \\
27 \text { Jul-3 Sept (39) }\end{array}$ & $\begin{array}{l}\text { Incubation } \\
\text { Chick rearing }\end{array}$ & $\begin{array}{l}11.0 \\
9.75\end{array}$ & $\begin{array}{r}0.24 \\
-0.09\end{array}$ & $\begin{array}{r}0.11 \\
-0.03\end{array}$ & $\begin{array}{l}-0.24 \\
-0.02\end{array}$ & $\begin{array}{r}0.41 \\
-0.12\end{array}$ & $\begin{array}{r}0.04 \\
-0.02\end{array}$ & $\begin{array}{l}-0.15 \\
-0.27\end{array}$ \\
\hline Selvagem Pequena (2008) & 10 Jun-2 Sept (85) & Incubation and chick rearing & $14.2,28.3$ & 0.07 & 0.03 & 0.12 & 0.21 & 0.02 & 0.01 \\
\hline
\end{tabular}

Significant correlations $(P<0.05)$ are marked in bold; NS: no significant period detected (see Methods). 

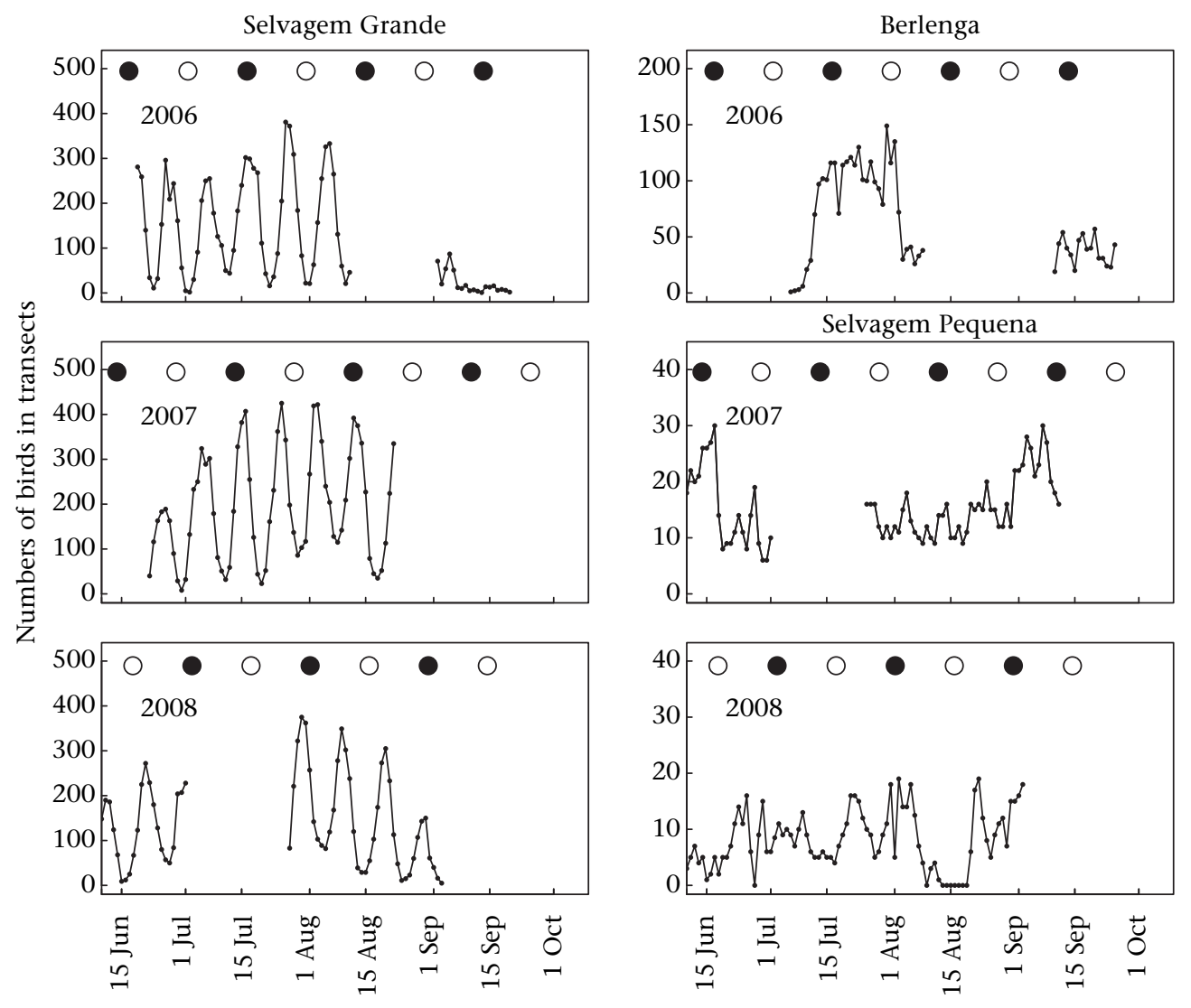

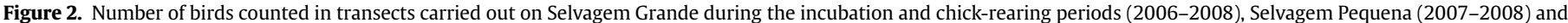
Berlenga (2006). Black and white circles represent new and full moon, respectively.

\section{Logging Bird Activity}

To examine the participation of individual breeding birds in the cycles, we deployed combined Global Location Sensing-immersion loggers (MK7 Geolocators, supplied by the British Antarctic Survey, Cambridge, U.K.; Afanasyev 2004) on 11 males and 13 females known to have bred in the previous seasons on Selvagem Grande. In addition to recording ambient light levels, these archival tags also check for saltwater immersion every $3 \mathrm{~s}$, and record every change of state from 'wet' (indicating sitting on the sea surface) to 'dry' (indicating flying or on land) that lasts more than $6 \mathrm{~s}$. Birds were caught by hand usually inside their burrows or in their vicinity. Loggers were fixed to normal-sized metal rings with a cable tie on 1-2 April 2007, and retrieved from 13 May onwards, providing activity (immersion) information for the period 2 April-12 May (two loggers failed to record data on 2 days). The loggers weigh ca. $3.5 \mathrm{~g}$ (less than $0.5 \%$ of the birds' weight) and apparently had no detrimental effects on the behaviour or performance of birds. The sex of tagged birds was determined by their distinctive calls or using a discriminant function based on bill measurements (Granadeiro 1993). Both mates take shifts during incubation and, with the exception of one male and one female, all tagged birds were later found incubating an egg.

Daily immersion profiles of tagged birds based on the duration of dry and wet periods recorded during the night allowed us to determine whether these birds visited the colony or remained at sea. In the vast majority of cases, examination of these immersion profiles enabled an unequivocal identification of periods ashore (e.g. very long dry periods, starting in late afternoon and lasting almost until dawn). In the few instances where results were more equivocal, birds showing an uninterrupted dry period longer than
$5 \mathrm{~h}$ during the night were considered to have come to the colony during the prelaying period; otherwise, they were considered to have remained at sea. In practice, even if this rule was conservative, any associated uncertainty would not influence any of the conclusions presented in this paper, because similar results were obtained regardless of whether the few doubtful records were all considered to represent attendance at the colony, or not.

\section{Chick Growth Parameters and Adult Diet}

To test for periodicity in provisioning patterns, a group of 60 chicks from Selvagem Grande were weighed daily with a spring balance (to the nearest $2 \mathrm{~g}$ or $5 \mathrm{~g}$ ) during the morning, between 11 August and 3 September 2008. For each day, we calculated the mean relative growth rate $\left(\left[\operatorname{Mass}_{t+1}-\right.\right.$ Mass $\left._{t}\right] /$ Mass $\left._{t},\right)$, the daily mass gain (mean of positive mass variation, a proxy for the size of meals, in $g$ ), and the proportion of chicks that were fed by their parents (i.e. those that increased their mass). We also present some preliminary data obtained from diet samples collected from adults in August 2008 on Selvagem Grande. Every other day, about 6-10 randomly selected adult birds (breeders and nonbreeders) were stomach-flushed with salt water as they landed in late afternoon. Samples were obtained by a modification of the technique initially proposed by Wilson (1984), and widely used in dietary studies of seabirds. We inserted a thin $(5 \mathrm{~mm})$ plastic tube through the bird's mouth, gently pumping sea water into its stomach then massaging their abdomen, which stimulated the flushing of the stomach content. No bird was sampled more than once and we only captured one member of a pair. No compensatory food was provided to sampled birds, but our procedures did not seem to affect the behaviour of birds unduly, and they did not desert their 

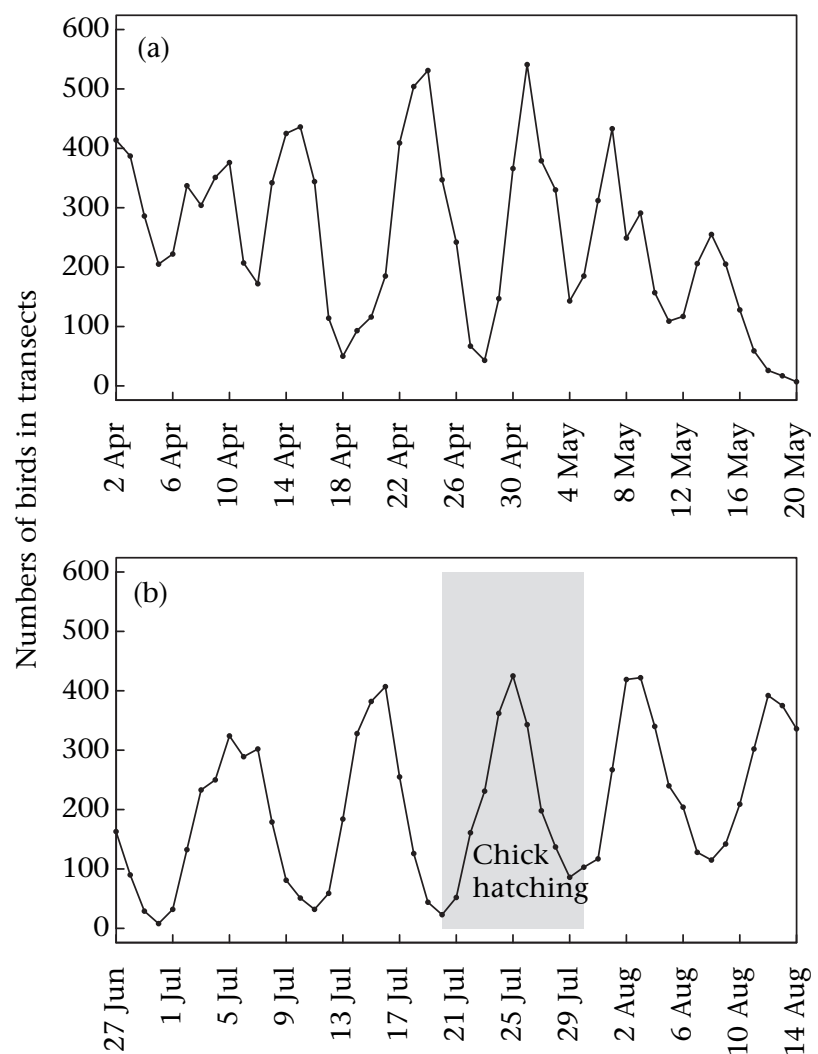

Figure 3. Comparison between counts carried out on Selvagem Grande during the (a) prelaying and (b) incubation/chick-rearing periods (2007). The hatching period is indicated in grey.

chicks after being sampled. For each sampling day, we calculated the proportion of samples containing cephalopods, as this might suggest a change in the main foraging areas.

\section{Statistical Procedures}

The significance of correlations between two time series was estimated using permutation tests (Manly 1998). All time series were detrended prior to the calculation of statistics to avoid spurious correlations, and so tests were carried out with the raw residuals of a linear or a loess fit, depending on the type of trend detected in the data. The test statistics were compared with a distribution of Pearson correlations obtained from randomizing the order of one of the series 9999 times, and considered to be significant if located in either of the 0.025 tails of that distribution.

For testing the significance of periods in the time series we also used randomization tests, following Manly (1998). Given a time series with $n$ elements (and assuming $m=n / 2$ and $w_{k}=2 \pi k / n$, $k=1$ to $(m-1))$, the series was modelled as:

$$
\begin{aligned}
x_{i}= & A(0)+\sum_{k=1 \text { to }(m-1)}\left\{A(k) \cos \left(w_{k} i\right)+B(k) \sin \left(w_{k} i\right)\right\} \\
& +A(m) \cos \left(w_{m} i\right)
\end{aligned}
$$

which can be solved to:

$$
\begin{aligned}
& A(0)=\operatorname{mean}(x) \\
& A(k)=2 / n \sum_{i=1 \text { to } n} x_{i} \cos \left(w_{k} i\right)
\end{aligned}
$$

$$
\begin{aligned}
& B(k)=2 / n \sum_{i=1 \text { to } n} x_{i} \sin \left(w_{k} i\right) \\
& A(m)=1 / n \sum_{i=1 \text { to } n} x_{i}(-1)^{i}
\end{aligned}
$$

Assuming that $S^{2}(k)=A^{2}(k)+B^{2}(k)$, one can compute a set of $p(k)$ values which estimates the proportion of variation in the series associated with the corresponding frequencies:

$$
\begin{aligned}
& \text { if } k<m \quad p(k)=S^{2}(k) / \sum_{i=1 \text { to } n}\left(x_{i}-\operatorname{mean}(x)\right)^{2} \\
& \text { if } k=m \quad p(k)=A(m) / \sum_{i=1 \text { to } n}\left(x_{i}-\operatorname{mean}(x)\right)^{2}
\end{aligned}
$$

The values of $p(k)$ obtained for a given time series (standardized to unit sum) are then compared with the corresponding distributions of $p^{\prime}(k)$ obtained after randomizing the order of the time series. The frequencies were considered to be significant if the corresponding $p(k)$ were contained in the 0.025 tails of the distributions (after Bonferroni adjustment of the critical value owing to the multiple tests of individual periodicities, Manly 1998). Statistical analysis and permutation tests were carried out using the free software environment R (R Development Core Team 2008).

\section{RESULTS}

\section{Characteristics of the Attendance Cycles}

From incubation to chick-rearing periods, the number of birds counted on the Selvagem Grande transect fluctuated between 1 and ca. 400 , and showed a very regular oscillation with significant periodicity of ca. 9-11 days (Fig. 2, Table 1). The average \pm SD duration of foraging trips on Selvagem Grande during the incubation period was $6.3 \pm 3.3$ days $(N=56$; Catry et al. 2009), thus bearing no relationship with the period of the cycles.

On Selvagem Pequena, a significant periodicity of 14.2 days (with a harmonic at 28 days) was detected in 2008, but this pattern was generally noisy and not apparent under visual examination (Fig. 2, Table 1). During prelaying, the cycles on Selvagem Grande lasted for 7.8 days and thus were shorter than in the subsequent breeding period (Fig. 3). There was no apparent cyclicity in attendance patterns on Berlenga Island in 2006 (Fig. 2).

To test whether cycles were in or out of phase in the three legs of the Selvagem Grande transect, we checked whether the highest cross-correlation among the legs was observed at lag 0 days or at higher lags in the five time intervals studied between 2006 and 2008 (listed in Table 1). In nine of the 15 possible cross-correlations we obtained the highest correlation at lag 1 or 2 days, and only six correlations at lag 0 . In fact, even the visual inspection of the data, for example during early chick rearing, suggests that there is a slight mismatch between the cycles at the three adjacent transect sectors (Fig. 4).

Cycles appeared to be synchronized between Selvagem Grande and Selvagem Pequena in $2007(r=0.54, N=39, P<0.001)$, but not in $2008(r=0.035, N=58, P=0.79)$. Also, there was no significant relationship between the numbers on Selvagem Grande and Berlenga Island in $2006(r=-0.09, N=43, P=0.55)$.

Mougin et al. (2000) examined the variation in numbers at Selvagem Grande for some periods between 1988 and 1996, expressing the periodicities as half cycles (i.e. as the number of days between consecutive minima and maxima). The prelaying half cycles derived from our data were significantly shorter than those Mougin et al. (2000) reported (mean $\pm \mathrm{SD}=3.5 \pm 1.1$ days, $N=11$ 


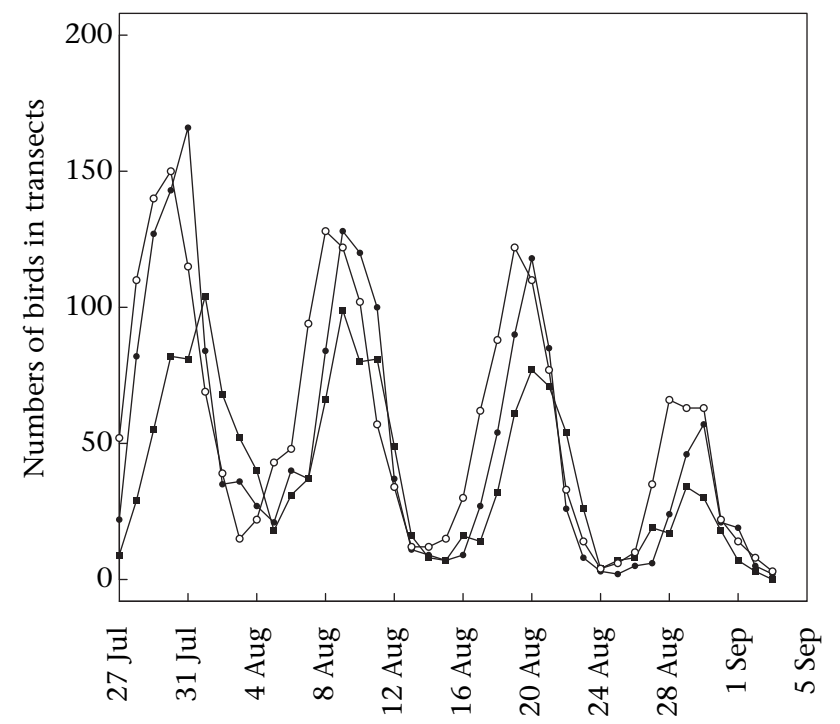

Figure 4. Out-phasing in the number of birds in the three legs of the transect carried out on Selvagem Grande during early chick rearing (2008).

in our study versus $4.8 \pm 1.3$ days, $N=39$ obtained by Mougin et al. 2000), but there was no difference during incubation and chick rearing (mean $\pm \mathrm{SD}=5.0 \pm 0.92$ days, $N=29$ in this study versus $4.8 \pm 1.6$ days, $N=50$, given by Mougin et al. 2000).

\section{Relationship with Wind Parameters and Moon Phase}

The Selvagens archipelago is dominated by northeasterly winds, and the mean wind speed $\pm S D$ during the period 1 April-15 September 2007 was $5.9 \pm 1.83 \mathrm{~m} / \mathrm{s}$. Overall, correlations between the numbers of birds on the island and the wind parameters were weak and inconsistent (Table 1). In 2007, numbers on Selvagem Grande showed a significant inverse relationship with the westerly component of wind during the prelaying period but were positively correlated with the northerly and westerly components during chick rearing (Table 1 ). We investigated the periodicity of northerly and westerly wind components and of wind intensity over the period 1998-2008 between 1 April and 15 May (prelaying period), and between 10 June and 1 September (incubation and chickrearing periods). None of the wind parameters presented the same periodicity more than twice in the 10-year series in either the area surrounding the Selvagens or at the African coast.

There was no relationship between moon phase and the number of birds attending any of the colonies, except in Selvagem Pequena between 10 June and 2 September 2008, when birds were more abundant ashore during the new moon $(r=-0.45, N=84$, $P<0.01$; Fig. 2).

\section{Cycles and Chick Provisioning}

To test the hypothesis of an oscillation in food abundance around Selvagem Grande, we examined the variation in provisioning patterns and in diet composition of adults. The number of birds ashore did not correlate with chick growth rates (expressed as the loess-detrended ratio: $r=0.14, N=38, P=0.41$ ), the proportion of chicks fed ( $r=0.17, N=38, P=0.31$, arcsine-transformed data), or the daily chick mass increments $(r=0.04, N=38, P=0.81$, mass detrended). Furthermore, chick growth parameters did not show any significant periodicity, as revealed by the periodicity analysis. Nor did we find any relationship between the proportion of cephalopods in the diet and the number of birds ashore $(r=0.11, N=18$ days, NS), which might be an indication of a major change in the foraging areas. The proportion of cephalopods in samples collected on the peak of bird abundance \pm 1 day $(0.19, N=36$ samples $)$ did not differ from that at minimum \pm 1 day $(0.29, N=54$ samples; $\left.\chi_{1}^{2}=0.70, P=0.40\right)$. Finally, virtually all the birds sampled outside a burrow (i.e. nonbreeding birds) had empty stomachs, whereas birds attending chicks generally had some food in the stomach.

\section{Behaviour of Individual Birds}

To test whether both breeders and nonbreeders were involved in the cycles, we examined data collected during the prelaying period from birds that had been fitted with loggers while breeding in the previous season. Overall, the proportion of marked females coming ashore decreased between 2 April and 12 May (slope $\pm \mathrm{SE}=-0.014 \pm 0.002, N=41, P<0.001)$, whereas that of males remained constant $(0.0005 \pm 0.0018, N=41$, NS), which led to significant differences in the average attendance of both sexes in this period (paired $t$ test: $t_{40}=7.16, P<0.001$; Fig. 5). Despite this difference, the proportion (detrended, in females) of marked birds that visited the island closely matched the changes in bird numbers counted in transects in both sexes (tagged males: $r=0.68$; tagged females: $r=0.56$; total: $r=0.67$, all $N=41$ days, $P<0.005$ ). Also, the probability of joint occurrence during peak counts was very high compared with that expected if birds were not engaged in cyclic attendance (calculated by multiplying the average attendance of males and females, dashed line in Fig. 5).

\section{DISCUSSION}

Our results on attendance cycles are based on several long time series that are, to the best of our knowledge, the most regular and
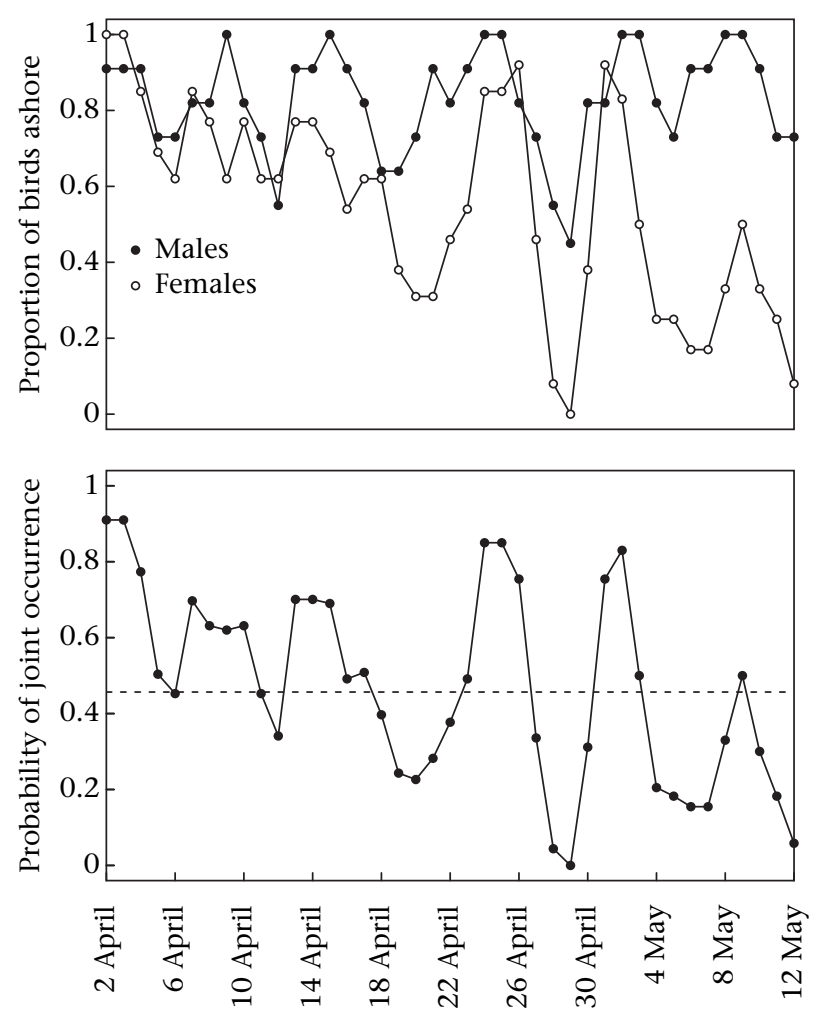

Figure 5. Variation in (a) the proportion of males and females marked with loggers that came ashore, and (b) the probability of joint occurrence resulting from this proportion (the average probability of joint occurrence is indicated as a dashed horizontal line). 
consistent ever published for any bird species. The detailed mechanisms by which such attendance cycles develop and are maintained remain mysterious, but our results none the less strongly refute some hypotheses, as well as provide some interesting insights. In particular, it is now clear that although cycles are very conspicuous at Selvagem Grande, a very large colony where birds come ashore during daylight, they are absent in the smaller colonies at Selvagem Pequena and Berlenga Island, where birds behave otherwise. Moreover, they are apparently slightly out of phase in adjacent sectors of one single colony.

Nonbreeders made up the bulk of the birds counted in transects, as they tend to remain out of crevices (being very vocal and often engaging in intense social interactions), whereas breeders tend to keep inside burrows; in June 2006, almost all breeders in one transect sector were marked on the breast with paint (for the purposes of a concurrent study), but the vast majority of birds seen during counts were unmarked. However, breeding birds were also involved in the cycles even before egg laying, as demonstrated by the cyclic variation in attendance of known breeders fitted with activity loggers.

The visibility hypothesis was not supported by our results, as the cycles were noticeable even in birds marked with loggers, whose presence was recorded by totally observer-independent processes.

The weather hypothesis was also not supported, as there was no consistent relationship between wind strength or direction and the number of birds ashore. Nor was there any periodicity in the wind fields over the last 10 years in the vicinity of the colony or at foraging grounds along the African coast. Wind strength and direction influence the foraging and migratory behaviour of a variety of seabirds (e.g. Furness \& Bryant 1996; Weimerskirch et al. 2000; Felicísimo et al. 2008). For example, Weidinger (1996) found that the attendance of Cape petrels was lower during periods of stronger southeasterly winds, possibly facilitating access to their preferred foraging grounds. Also, in the northern fulmar, Fulmarus glacialis, colony attendance was higher when wind speeds were low near the colony, because birds avoid incurring increased costs of flight (Hatch 1989; Furness \& Bryant 1996), yet the opposite patterns have been reported in auklets and guillemots (Birkhead 1978; Piatt et al. 1990). None the less, the prevailing wind regime does not seem to exert a strong and persistent influence on bird numbers at Selvagem Grande. In addition, we are not aware of any site or circumstance where wind conditions present a level of short-term cyclicity that could sustain such a synchronized and durable phenomenon as that observed at Selvagem Grande.

The oceanography/food availability hypothesis was also unsupported by our study. If changes in shearwater numbers ashore were brought about by sudden peaks of food availability near the colony (owing to vertical or horizontal currents, temperature changes, prey movements, etc.), we would expect a measurable correspondence with variation in chick-provisioning parameters or in the diet of adults. However, we could not find any relationship between number of birds in transects and the proportion of chicks fed, meal mass or chick growth rate. Also, we would predict that nonbreeders would have food in their stomachs, which was also not the case.

Tidal and lunar cycles are also important drivers of many coordinated phenomena observed in marine biota (reviewed in McDowall 1969). For example, several prey species (particularly zooplankton and mesopelagic fish) migrate to the surface during the new moon and thus their availability for surface-feeding seabirds can show some periodicity (e.g. Linkowski 1996; Hernández-León et al. 2001; Hernández-León, 2008). Furthermore, nocturnal light levels may influence activity patterns of visual predators such as shearwaters (Yamamoto et al. 2008). If such patterns were to influence the attendance at Selvagem Grande, we should be able to find a relationship between bird numbers and the moon phase (and consequently also with tidal range). However, we did not find any such correlations, confirming previous observations at the same site (Jouanin et al. 1989; Mougin et al. 2000). Furthermore, the periodicity of the cycles at Selvagem Grande bears no relationship to the periodicity of the lunar cycle.

The social encounters hypothesis is probably best tested by comparative studies such as the one by Mougin et al. (2000). However, our results support the idea that attendance cycles facilitate encounters between socially relevant contacts. First, we confirmed that coordinated attendance of males and females led to an increase in the probability of joint occurrence of nesting partners in periods of high attendance. Second, we should expect cycles to be the norm in colonies in pelagic environments (where birds typically forage for long periods away from the colony), and facultative in coastal colonies where a higher food abundance should enable birds to come ashore more often. Hence, the absence of well-defined cycles at Berlenga is in line with this hypothesis. Berlenga is situated on the continental shelf and birds from this colony make shorter foraging trips than at Selvagem (Granadeiro et al. 1998; Catry et al. 2009), which allows a more regular attendance at the colony and more frequent encounters between individuals. On the other hand, the presence of cycles at Selvagem Grande and their absence (or lack of definition) at both Selvagem Pequena and Berlenga challenges the idea that the existence of attendance cycles is dependent solely on the length of the pre-egg stage, as proposed by Mougin et al. (2000): the duration of the preegg stage is similar at Berlenga and Selvagem (Granadeiro 1991), yet the attendance behaviour clearly differed between these islands.

One of the predictions of the endogenous rhythm hypothesis is that the periodicity of cycles should be fairly constant. Circadian and circannual rhythms are a common trait in a variety of taxa and are relatively well documented in birds (Dunlap et al. 2004; Wikelski et al. 2008), but there is little evidence for cycles with a periodicity broadly similar to the one reported here (ca. 9 days). Ellis et al. (2006) documented an oscillation in moult intensity of a golden eagle, Aquila chrysaetos, with a periodicity of 19 days, while Bairlein (1986) noted average 18-day cycles in the body mass of garden warblers, Sylvia borin. Evidence for the endogenous rhythm hypothesis is somewhat mixed in our results. In fact, there was an exceptional degree of regularity of cycles across years, and during both incubation and chick rearing at Selvagem Grande, with the cycle period rarely deviating by much more than 1-2 days (Jouanin et al. 1989; this study). On the other hand, preincubation cycles on this island were slightly shorter than during other phases of the breeding cycle. Furthermore, cycles at nearby Selvagem Pequena showed no regularity across years and their periodicity differed from that recorded at Selvagem Grande. Note that both colonies differ in other important aspects, particularly in that only at Selvagem Grande do birds come ashore during daylight in large numbers, and also that colony size differs by two orders of magnitude between the two islands. It is possible that, even if there is an endogenous rhythm, attendance cycles can only develop where large numbers of birds are simultaneously present, providing a strong social stimulus.

The social stimulus hypothesis suggests that it is the social interactions at the colony that somehow drive the cycles (for example, by providing an entrainment agent for an endogenous rhythm). The information available on the social modulation of endogenous rhythms in birds mostly relates to circadian (e.g. Menaker \& Eskin 1966; Gwinner 1967; Favreau et al. 2009) or circannual (mostly migratory) rhythms (e.g. Gwinner 1996; Wikelski et al. 2008), with few data on other types of cycles. Such a lack of information obviously makes it difficult to progress with this 
hypothesis. However, the apparent slight out-phasing of cycles in different areas of the island supports the idea that local processes (such as social interactions) may influence synchronization among individuals. Also, the cycles were only found in a large colony, where birds are extremely vocal and reactive to neighbours both on the ground and in flight. Cycles were absent in smaller colonies (Berlenga, Selvagem Pequena) and are unreported elsewhere in this species. Clearly, this is an area where more basic research is badly needed.

\section{Conclusions}

This study demonstrates not only the remarkable consistency and conspicuousness of the attendance cycles of Cory's shearwater at Selvagem Grande, but also the variability in behaviour at nearby or distant colonies. Our results support the existence of an endogenous cycle, probably sustained by intense social stimulation at the colonies, and so marked cycles are probably more likely to occur in dense colonies. While the possible benefits of these cycles are relatively clear, the exact mechanisms through which they are controlled are still completely unknown. Clearly, the topic deserves more research, including more comparative studies.

\section{Acknowledgments}

We thank the Parque Natural da Madeira for permission to carry out work on Selvagem Gande and all the wardens for helping to make our stay enjoyable. We are particularly grateful to Paulo Oliveira for his continuing support and also to the nature wardens involved in counting birds at Selvagem Pequena. We also thank Rafael Matias and Luís Vicente for carrying out the bird counts during their stay at Selvagem Grande and Berlenga islands, respectively. Jaime A. Ramos helped with fieldwork and Maria P. Dias provided useful comments on the manuscript. NCEP reanalysis data were provided by the NOAA/ OAR/ESRL PSD, Boulder, Colorado, U.S.A. from their web site at http:// www.cdc.noaa.gov/. This study is an output from a project on the ecology of Cory's shearwaters (POCTI/MAR/58778/2004) supported by Fundação para a Ciência e a Tecnologia (FCT-Portugal). P. Catry and $\mathrm{H}$. Alonso benefited from fellowships from FCT (BPD/11631/02 and SFRH/BD/47055/2008, respectively).

\section{References}

Afanasyev, V. 2004. A miniature daylight level and activity data recorder for tracking animals over long periods. Memoirs of National Institute of Polar Research (Japan), Special Issue, 58, 227-233.

Birkhead, T. R. 1978. Attendance patterns of guillemots Uria aalge at breeding colonies on Skomer Island. Ibis, 120, 219-229.

Bretagnolle, V. 1988. Cycles de présence et rythmes d'activité chez cinq espèces de pétrels antarctiques. L'Oiseau et la R.F.O., 58, 44-59.

Bretagnolle, V. 1990. Effet de la lune sur l'activité des pétrels (classe Aves) aux îles Salvages (Portugal). Canadian Journal of Zoology, 68, 1404-1409.

Catry, P., Matias, R., Vicente, L. \& Granadeiro, J. P. 2009. Brood-guarding behaviour in Cory's shearwaters Calonectris diomedea. Journal of Ornithology, 150, 103-108.

Dunlap, J. C., Loros, J. J. \& DeCoursey, P. J. 2004. Chronobiology: Biological Timekeeping. Sunderland, Massachusetts: Sinauer Associates.

Ellis, D. H., Lish, J. W., Kery, M. \& Redpath, S. M. 2006. Short-term oscillations in avian moult intensity: evidence from the golden eagle Aquila chrysaetos. Journal of Avian Biology, 37, 642-644.

Equipa Atlas 2008. Atlas das Aves Nidificantes em Portugal (1999-2005). Lisboa: Instituto da Conservação e da Biodiversidade, Sociedade Portuguesa para o Estudo das Aves, Parque Natural da Madeira e Secretaria Regional da Ambiente e do Mar. Assírio \& Alvim.

Favreau, A., Richard-Yris, M.-A., Bertin, A., Houdelier, C. \& Lumineau, S. 2009. Social influences on circadian behavioural rhythms in vertebrates. Animal Behaviours, 77, 983-989.
Felicísimo, Á. M., Muñoz, J. \& González-Solis, J. 2008. Ocean surface winds drive dynamics of transoceanic aerial movements. PLOS ONE, 3, e2928, doi:10.1371 journal.pone.0002928.

Furness, R. W. \& Bryant, D. M. 1996. Effect of wind on field metabolic rates of breeding northern fulmars. Ecology, 77, 1181-1188.

Granadeiro, J. P. 1991. The breeding biology of Cory's shearwater Calonectris diomedea borealis on Berlenga Island, Portugal. Seabird, 13, 30-39.

Granadeiro, J. P. 1993. Variation in measurements of Cory's shearwater between populations and sexing by discriminant analysis. Ringing $\mathcal{E}$ Migration, 14, 103-112.

Granadeiro, J. P., Nunes, M. \& Furness, R. W. 1998. Flexible foraging strategy of Cory's shearwater, Calonectris diomedea, during the chick-rearing period. Animal Behaviour, 56, 1169-1176.

Granadeiro, J. P., Dias, M. P., Rebelo, R., Santos, C. D. \& Catry, P. 2006. Numbers and population trends of Cory's shearwater Calonectris diomedea at Selvagem Grande, Northeast Atlantic. Waterbirds, 29, 56-60.

Gwinner, E. 1967. Entrainment of a circadian rhythm in birds by species-specific song cycles. Experientia, 22, 765-766.

Gwinner, E. 1996. Circadian and circannual programmes in avian migration. Journal of Experimental Biology, 199, 39-48.

Harding, A. M. A., Piatt, J. F., Byrd, G. V., Hatch, S. A., Konyukhov, N. B. Golubova, E. U. \& Williams, J. C. 2005. Variability in colony attendance of crevice-nesting horned puffins: implications for population monitoring. Journal of Wildlife Management, 69, 1276-1296.

Harris, M. P. 1984. The Puffin. London: T. \& A.D. Poyser.

Hatch, S. A. 1989. Diurnal and seasonal patterns of colony attendance in the northern fulmar, Fulmarus glacialis, in Alaska. Canadian Field Naturalist, 103 248-260.

Hatch, S. A. 2002. Activity patterns and monitoring numbers of horned puffins and parakeet auklets. Waterbirds, 25, 348-357.

Hernández-León, S. 2008. Natural variability of fisheries and lunar illumination: a hypothesis. Fish and Fisheries, 9, 138-154.

Hernández-León, S., Almeida, C., Yebra, L., Arístegui, J., Hernández de Puelles, J. \& García-Braun, J. 2001. Zooplankton biomass in subtropical waters: is there a lunar cycle? Science Marine, 65, 59-64.

Jouanin, C., Roux, F. \& Mougin, J.-L. 1989. Cycles d'affluence des puffins cendrés (Calonectris diomedea borealis) à Selvagem Grande. L'Oiseux et R.F.O., 59, 153-168.

Linkowski, T. B. 1996. Lunar rhythms of vertical migrations coded in otolith microstructure of North Atlantic lanternfishes, genus Hygophum (Myctophidae). Marine Biology, 124, 495-508.

McDowall, R. M. 1969. Lunar rhythms in aquatic animals: a general review. Tuatara 17, 133-145.

Magalhães, M. C., Santos, R. S. \& Hamer, K. C. 2008. Dual-foraging of Cory's shearwaters in the Azores: feeding locations, behaviour at sea and implications for food provisioning of chicks. Marine Ecology Progress Series, 359, 283-293.

Manly, B. F. J. 1998. Randomization, Bootstrap and Monte Carlo Methods in Biology, 2nd edn. London: Chapman \& Hall.

Menaker, M. \& Eskin, A. 1966. Entrainment of circadian rhythms by sound in Passer domesticus. Science, 154, 1579-1581.

Mougin, J. L. \& Jouanin, C. 1997. Prospection alimentaire du puffin cendré Calonectris diomedea borealis de Selvagem Grande $\left(30^{\circ} 9^{\prime} \mathrm{N}, 15^{\circ} 52^{\prime} \mathrm{W}\right)$ pendant l'incubation, par télémétrie satellitaire. Comptes Rendus de l'Académie des Sciences, 320, 825-831.

Mougin, J.-L., Jouanin, C. \& Roux, F. 2000. The attendance cycles of the Cory's shearwater Calonectris diomedea borealis of Selvagem Grande. Comptes Rendus d'l Académie des Sciences, 323, 385-390.

Piatt, J. F., Roberts, B. D. \& Hatch, S. A. 1990. Colony attendance and population monitoring of least and crested auklets on St. Lawrence island, Alaska. Condor 92, 97-106.

R Development Core Team 2008. $R$ : a Language and Environment for Statistical Computing. Vienna: R Development Core Team. http://www.R-project.org.

Weidinger, K. 1996. Effects of weather on the cyclic patterns of colony attendance in the Cape petrel Daption capense. Polar Biology, 16, 339-344.

Weimerskirch, H., Guionnet, T., Martin, J., Shaffer, S. A. \& Costa, D. P. 2000. Fast and fuel efficient? Optimal use of wind by flying albatrosses. Proceedings of the Royal Society B, 267, 1869-1874.

Wilhelm, S. I. \& Storey, A. E. 2002. Influence of cyclic pre-lay attendance on synchronous breeding in common murres. Waterbirds, 25, 156-163.

Wilson, R. P. 1984. An improved stomach pump for penguins and other seabirds. Journal of Field Ornithology, 55, 109-112.

Wikelski, M., Martin, L. B., Scheuerlein, A., Robinson, M. T., Robinson, N. D. Helm, B., Hau, M. \& Gwinner, E. 2008. Avian circannual clocks: adaptive significance and possible involvement of energy turnover in their proximate control. Philosophical Transactions of the Royal Society B, 363, 411-423.

Yamamoto, T., Takahashi, A., Yoda, K., Katsumata, N., Watanabe, S., Sato, K. \& Trathan, P. N. 2008. The lunar cycle affects at-sea behaviour in a pelagic seabird, the streaked shearwater Calonectris leucomelas. Animal Behaviour, 76 1647-1652. 